\title{
Viscosity of diluted suspensions of vegetal particles in water
}

\author{
Adriana Szydłowska*, and Jerzy Hapanowicz \\ Department of Process Engineering, Faculty of Mechanical Engineering, Opole University of Technology, Poland
}

\begin{abstract}
Viscosity and rheological behaviour of sewage as well as sludge are essential while designing apparatuses and operations employed in the sewage treatment process and its processing. With reference to these substances, the bio-suspensions samples of three size fractions ((i) $150 \div 212 \mu \mathrm{m}$, (ii) $106 \div 150 \mu \mathrm{m}$ and (iii) below $106 \mu \mathrm{m}$ ) of dry grass in water with solid volume fraction $8 \%, 10 \%$ and $11 \%$ were prepared. After twenty four hours prior to their preparation time, the suspension samples underwent rheometeric measurements with the use of a rotational rheometer with coaxial cylinders. On the basis of the obtained results, flow curves were plotted and described with both the power model and Herschel-Bulkley model. Moreover, the viscosity of the studied substances was determined that allowed to conclude that the studied bio-suspensions display features of viscoelastic fluids. The experimentally established viscosity was compared to the calculated one according to Manley and Manson equation, recommended in the literature. It occurred that the measured viscosity values substantially exceed the calculation viscosity values, even by 105 times. The observations suggest that it stems from water imbibition of fibrous vegetal particles, which causes their swelling and decreases the amount of liquid phase in the suspension.
\end{abstract}

\section{Introduction}

Sewage treatment is a very complex process because it consists of many operations, e.g. piping transport, mixing, aeration or sedimentation [1]. In turn, sewage which is not subjected to purification is sometimes applied as a heat source forced through heat pumps [2]. In order to achieve a correct design of the apparatuses within the process of sewage processing (in terms of effectiveness and profitability), knowledge of these substances viscosity in various process conditions is essential. The viscosity influences mainly the suspensions flow pattern, their flow resistances, the phenomena of heat transfer and also the velocity of solid particles settling or gas bubbles lifting. The viscosity is a parameter depending not only on the temperature. Its value may also result from the solid concentration, the solid properties and also the shear time and shear rate bound up with the flow velocity in a pipe or a mixing intensity in a tank. Fluctuations of suspensions viscosity can be verified due to the rheometeric measurement results of these fluids. The rheometeric measurements are the most state-of-the-art and desirable in the wastewater treatment sector as well as in many other fields of industry what is mentioned by the authors of the papers $[3,4]$.

Sewage rheology became an important research subject in the early eighties of the last century and it resulted from increasing population of people and, thus an increasing amount of sewage which could not be stored in any way [4]. Since then, a stronger emphasis has been placed on increased efficiency of the sewage treatment process while keeping costs as low as possible.

The fact that rheology belongs to one of the most important fields of knowledge, which allows to design the sewage treatment process correctly, is confirmed by numerous articles concerning this issue, inter alia [1,38]. The authors of these articles recognize unanimously the sewage as non-Newtonian fluids which do not obey the Newton's law of viscosity

$$
\eta=\frac{\tau}{\dot{\gamma}}
$$

in which $\eta$ means a coefficient of dynamic viscosity $[\mathrm{Pa} \cdot \mathrm{s}], \tau$ is shear stress $[\mathrm{Pa}]$ and $\dot{\gamma}$ is shear rate $\left[\mathrm{s}^{-1}\right]$. However, as far as determination of the rheological behaviour of sewage is concerned, the scientists' opinions are divided. In articles [2,7] it has been proven that sewage can be treated as shear-thinning substance whereas the authors of the article [6] revealed that sewage belongs to viscoelastic fluids with yield stress. Due to the difficulties with elaboration of the correct measurement methodology, the establishment of the rheological stability of sewage has not been successful yet [5]. Unequivocal rheological classification of sewage may be considered burdensome due to its very complex composition and structure. Sewage constitutes a multiphase system formed by water, long-chain polymers, bacteria, colloids, flocculants and also particles of organic origin including vegetal origin [5]. In addition, the designation of the sewage rheological

\footnotetext{
* Corresponding author: a.szydlowska@doktorant.po.edu.pl
} 
behaviour may sometimes seem inconclusive as a consequence of its continuously changing inner structure.

Usually, although the rheometeric measurements of sewage are extensive, they are limited to the establishment of the rheological characteristics of different kinds of sewage sludge [9] e.g. activated sludge [3] or digested sludge [7] which is partly recirculated. Additionally, changes of the physical properties of the studied sludge are indicated. The changes result from the impact of the subsequent physical and chemical processes of successive stages within the waste-water treatment processes. The impact of the solid concentration and the grain geometry of the solid in the sludge on the rheological properties is also investigated $[8,10]$. However, the literature of the subject reveals insufficient information about spontaneous changes of sewage physical properties, which should interplay with their rheological properties. Hence, the primary aim of this paper is to determine the viscosity of the biosuspensions samples which were prepared in advance. In order to investigate whether the time of existence of biosuspension affects their rheological properties, suspensions samples of vegetal particles in water were studied.

\section{Materials and methods}

The aqueous suspensions of dry grass (of hay) were measured. Such a solid indubitably occurs in sewage sludge and furthermore, a combination of water (as well as an aqueous solution) with a vegetal solid is found in various industry sectors.

The solid was milled and sieved and, as a result, three solid size fractions were obtained: (i) $150 \div 212 \mu \mathrm{m}$, (ii) $106 \div 150 \mu \mathrm{m}$ and (iii) below $106 \mu \mathrm{m}$. It was assumed that the particles of the applied vegetal material constitute elements of fibres with size that suits a given fraction. The suspensions with the solid volume fraction of each of the fractions equal to $8 \%, 10 \%$ and $11 \%$ (the solid mass fraction of the samples equals $9 \%, 11 \%$ and $13 \%$ respectively) underwent the rheometeric measurements. The samples were prepared according to the gravimetric method what required earlier determination of the solid real density. The physical properties of the suspensions components and the suspensions notations which were used for the needs of the results documentation are compiled in Table 1.

The volume of the prepared samples corresponded to the measuring gap capacity of the rheometer and it was equal to $25 \mathrm{~cm}^{3}$. Operating with the solid mass fraction, the earlier calculated masses of the solid were measured out and appropriate amounts of water were added.

The viscosity measurements were conducted with the rotational rheometer with coaxial cylinders similarly to the other researchers $[7,8,11,12]$. A set of cylinders with the width of a measuring gap equal to $2 \mathrm{~mm}$ was applied. The measurements were performed at a temperature of $21^{\circ} \mathrm{C} \pm 1^{\circ} \mathrm{C}$ within the range of shear rate from $1 \mathrm{~s}^{-1}$ to $437 \mathrm{~s}^{-1}$ which corresponds, among others, to such processes like forcing in a pipe or mixing in a tank. In order to consider the phenomena occurring in sewage sludge which is processed for tens of hours, the prepared suspensions underwent the measurements after twenty four hours since their preparation time. It allowed to consider the changes of the solid physical parameters resulting from the contact between the solid and water.

Table 1. The suspensions physical properties and their accepted notations

\begin{tabular}{|c|c|c|c|}
\hline Material & \multicolumn{3}{|c|}{ Real density $\left[\mathrm{kg} / \mathrm{m}^{3}\right]$} \\
\hline Water & \multicolumn{3}{|c|}{998.5} \\
\hline Hay & \multicolumn{3}{|c|}{1175.0} \\
\hline \multirow{2}{*}{$\begin{array}{l}\text { Accepted } \\
\text { notations }\end{array}$} & \multirow{2}{*}{$\begin{array}{l}\text { Size fraction } \\
{[\mu \mathrm{m}]}\end{array}$} & \multicolumn{2}{|c|}{ Solid fraction } \\
\hline & & vol. \% & wt. $\%$ \\
\hline S-I-8 & \multirow{3}{*}{$\begin{array}{c}\text { (i) } \\
150 \div 212\end{array}$} & 8 & 9 \\
\hline S-I-10 & & 10 & 11 \\
\hline S-I-11 & & 11 & 13 \\
\hline S-II-8 & \multirow{3}{*}{$\begin{array}{c}\text { (ii) } \\
106 \div 150\end{array}$} & 8 & 9 \\
\hline S-II-10 & & 10 & 11 \\
\hline S-II-11 & & 11 & 13 \\
\hline S-III-8 & \multirow{3}{*}{$\begin{array}{c}\text { (iii) } \\
\text { below } 106\end{array}$} & 8 & 9 \\
\hline S-III-10 & & 10 & 11 \\
\hline S-III-111 & & 11 & 13 \\
\hline
\end{tabular}

The samples were prepared in leakproof vessels which prevented from evaporation of water. However, a fluidity loss of some samples occurred during the experiments, which caused limitations within the range of shear rate.

\section{Results and discussion}

The results of rheometeric measurements allowed to plot the flow curves of the studied suspensions in the established range of the shear rate changes. The studied samples displayed features of non-Newtonian fluids, therefore their flow curves were primarily established for determination with the use of the power model

$$
\tau=k \dot{\gamma}^{n}
$$

which is depicted in the literature of the subject accordingly, since employing the equation (2) to describe the flow curves of the sewage sludge is frequently used. In model (2) symbols $k$ and $n$ constitute its parameters which correspond to the substance consistency and the tendency of its viscosity changes in function of the shear rate, respectively. Values of the parameters $k$ and $n$ for each of the studied samples together with the values of the coefficient of determination $\mathrm{R}^{2}$ are compiled in Table 2 .

The obtained values of the model (2) parameters for each of the suspensions suggest very high viscosity of the suspensions and a strong downward trend. Simultaneously, substantially high values of the parameter $k$ can indicate the studied substances are endowed with the yield stress. The best way to verify that assumption would be an experiment which would analyse relationships between the shear stress in function of very low values of shear rates. However, due to a 
more qualitative than quantitative character of the conducted analysis, the occurrence of the yield stress of the studied substances was verified in a theoretical way.

Table 2. Parameters of models (2) for the studied biosuspensions.

\begin{tabular}{|c|c|c|c|c|}
\hline $\begin{array}{c}\text { Size } \\
\text { fraction } \\
{[\mu \mathrm{m}]}\end{array}$ & vol. \% & $\begin{array}{c}\mathrm{k} \\
{\left[\mathrm{Pa} \cdot \mathrm{s}^{\mathrm{n}}\right]}\end{array}$ & $\begin{array}{c}\mathrm{n} \\
{[-]}\end{array}$ & $\begin{array}{c}\mathrm{R}^{2} \\
{[-]}\end{array}$ \\
\hline \multirow{2}{*}{$\begin{array}{c}\mathrm{i}) \\
150 \div 21\end{array}$} & 8 & 97.99 & 0.14 & 0.10 \\
\cline { 2 - 5 } 2 & 10 & 127.38 & 0.36 & 0.99 \\
\hline \multirow{2}{*}{$\begin{array}{c}\text { ii) } \\
106 \div 15\end{array}$} & 8 & 346.33 & 0.12 & 0.99 \\
\cline { 2 - 5 } 0 & 10 & 194.52 & 0.15 & 0.92 \\
\hline (iii) & 8 & 431.97 & 0.11 & 0.97 \\
\cline { 2 - 5 } below & 10 & 74.33 & 0.36 & 0.96 \\
\cline { 2 - 5 } 106 & 11 & 126.21 & 0.25 & 0.97 \\
\hline
\end{tabular}

Consequently, Herschel-Bulkley model was employed

$$
\tau=\tau_{y}+\eta_{p} \dot{\gamma}^{m}
$$

because if the substance has the yield stress, the model (3) will be more accurate (successful) than the model (2). Model (3) is rather dedicated to concentrated suspensions, than diluted ones, however, its application in this case is justified by parameters values of model (2) which turned out to be peculiar for the studied diluted suspensions. In the equation (3) the symbol $\tau_{y}$ is a yield stress $[\mathrm{Pa}]$, while $\eta_{p}$ means the so-called plastic viscosity $\left[\mathrm{Pa} \cdot \mathrm{s}^{\mathrm{m}}\right]$. The obtained values of model (3) parameters for individual bio-suspensions are compiled in s. Due to an insufficient number of the measuring points for the suspensions with the solid volume fraction equal to $11 \%$, a description of the points distribution with the model (3) was impossible.

Table 3. Parameters of models (3) for the studied biosuspensions.

\begin{tabular}{|c|c|c|c|c|c|}
\hline $\begin{array}{c}\text { Size } \\
\text { fraction } \\
{[\mu \mathrm{m}]}\end{array}$ & vol.\% & $\begin{array}{c}\tau_{\mathrm{y}} \\
{[\mathrm{Pa} \cdot \mathrm{s}]}\end{array}$ & $\begin{array}{c}\eta_{\mathrm{p}} \\
{\left[\mathrm{Pa} \cdot \mathrm{s}^{\mathrm{m}}\right]}\end{array}$ & $\begin{array}{c}\mathrm{m} \\
{[-]}\end{array}$ & $\begin{array}{c}\mathrm{R}^{2} \\
{[-]}\end{array}$ \\
\hline \multirow{2}{*}{$\begin{array}{c}\mathrm{i}) \\
150 \div \\
212\end{array}$} & 8 & 129.4 & 6.28 & 0.48 & 1.00 \\
\cline { 2 - 6 } & 10 & 110.72 & 32.95 & 0.76 & 0.99 \\
\hline \multirow{2}{*}{$\begin{array}{c}\text { (ii) } \\
106 \div \\
150\end{array}$} & 8 & 100.2 & 1.16 & 1.48 & 0.99 \\
\cline { 2 - 6 } & 11 & 137.37 & 61.58 & 0.26 & 0.97 \\
\hline \multirow{2}{*}{$\begin{array}{c}\text { (iii) } \\
\text { below } \\
106\end{array}$} & 8 & 24.13 & 1.81 & 0.61 & 0.98 \\
\cline { 2 - 6 } & 10 & 92.86 & 18.19 & 0.43 & 0.99 \\
\hline \multirow{2}{*}{} & 11 & \multicolumn{5}{|c}{-} \\
\hline
\end{tabular}

The evaluation of the obtained values corresponding to model (3) parameters allows to state the substances subjected to the rheometeric measurements may be characterized by the yield stress. It constitutes a substantial peculiarity due to the fact that the prepared bio-suspensions should be classified as dilute where water constitutes their liquid phase that is Newtonian liquid with low viscosity. It is also worth highlighting that a slight increase of solid fraction results in a significant increase in the studied bio-suspensions viscosity.

The research results assessment also based on a comparison of the suspension viscosity values and the trend of their changes against the viscosity of a pure liquid phase as well as suspension viscosity calculated according to Manley and Manson equation

$$
\eta_{z}=\eta_{c}\left(1+2,5 \phi+10,05 \phi^{2}\right)
$$

which is recommended in the literature [13] as a typical equation for this kind of two-phase systems. In the equation (4): $\eta_{z}$-delineates suspension viscosity $[\mathrm{Pa} \cdot \mathrm{s}]$; $\eta_{c}$ - is the viscosity of a liquid phase [Pa.s]; $\phi$ - is solid volume fraction [-]. This equation is recommended to calculate suspensions viscosity with up to $30 \%$ of solid volume fraction. Lack of parameters requiring extra measurements such as e.g. maximum solid fraction is an advantage of this equation. In Fig. 1-3 the viscosity of the studied bio-suspensions resulting from the measurements is shown against the background of the values calculated according to (4) and the viscosity of the liquid phase.

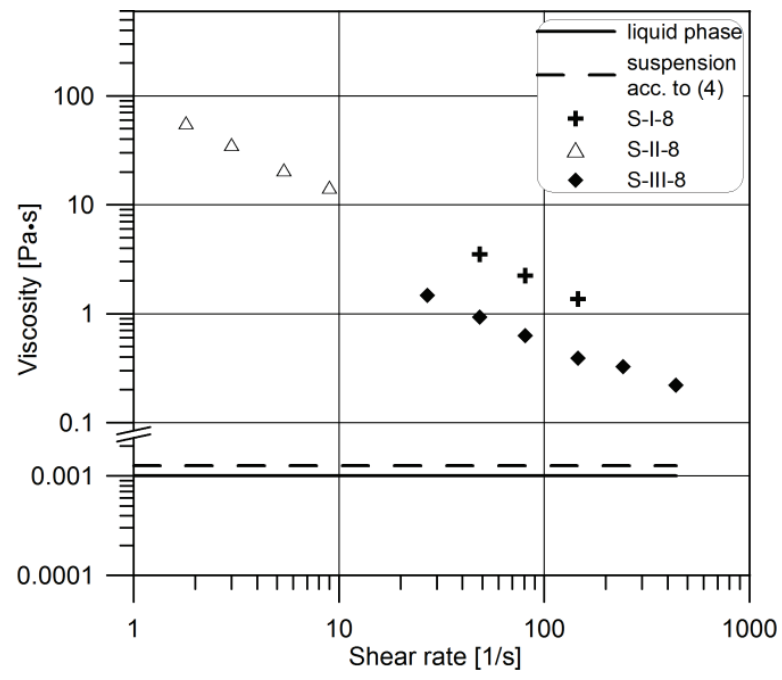

Fig. 1. Viscosity of bio-suspension with 8 vol.\% solid fraction.

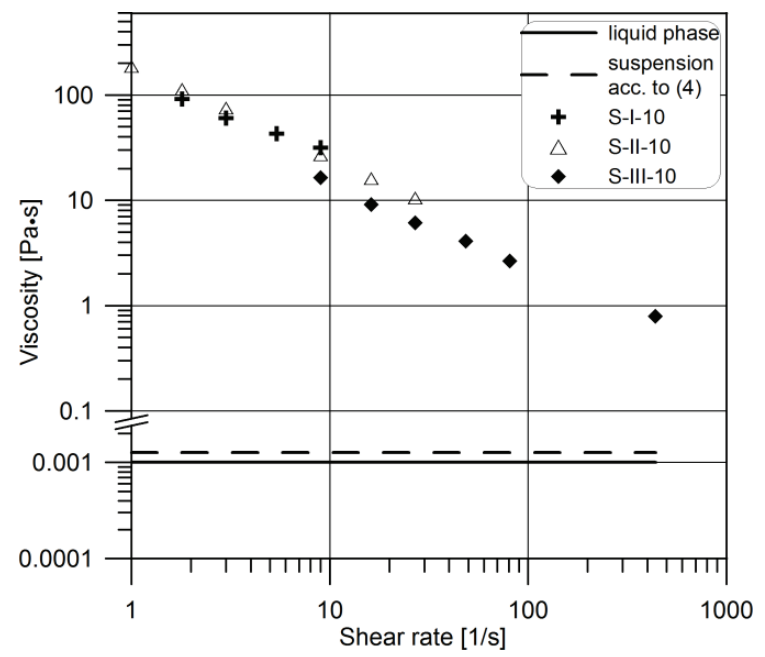

Fig. 2. Viscosity of bio-suspension with 10 vol.\% solid fraction. 


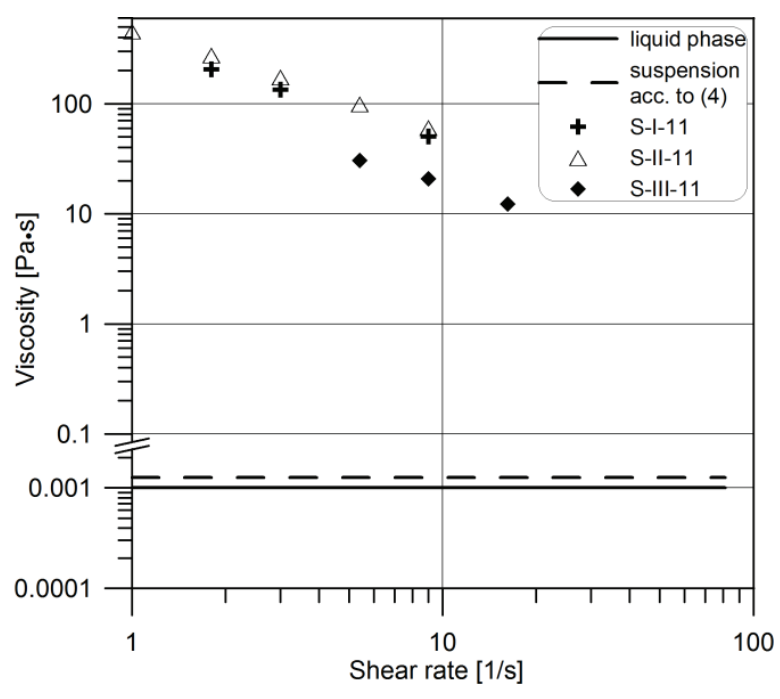

Fig. 3. Viscosity of bio-suspension with 11 vol.\% solid fraction.

Basing on the graphs pinpointed in the Figs. 1-3, it is possible to conclude that the trend of the bio-suspensions viscosity fluctuations is strongly downward. Yet, the fact that the measured viscosity values are either slightly over or five times higher than the viscosity values calculated according to (4) is even more significant. Apart from that, such a model (4) (like many other models dedicated to suspensions) cannot average the real results as it does not predict substance viscosity changes in a function of the shear rate. Investigating the points of distribution in the graphs, the impact of the solid size fraction on the values of the bio-suspension viscosity is easy to notice.

Yet, analysing the conditions of the rheometeric research it has to be added that a distinct increase of solid sizes and a partial disappearance of the liquid phase occurred in the samples of the suspensions prepared in advance. This effect corresponds to vegetal particles imbibition due to partial water absorption by the particles and it results in the increase of the solid volume fraction in the suspension. Thereby, the discussed measurement results can be treated as concerning concentrated suspensions what should exclude a surprise factor.

\section{Conclusions}

The major conclusion stemming from the conducted analysis concerns the duration of vegetal particles presence in a given multiphase system, which can affect the viscosity of the sewage (and any other aqueous biosuspension) and their rheological behaviour. The contact of the phases results in a partial imbibition of the liquid by the particles and, consequently, it leads to both an increase in their size and a decrease of the volume of the unbounded liquid phase. As a result, the bio-suspension with the specified concentration of the dry matter and the specified original size of the grains comes into existence. Though, in fact it is the multiphase system, which exhibits problematic parameters for an unequivocal quantitative adjudication. Such a substance would be characterized with completely different rheological properties other than the typical suspension containing grains which do not undergo the imbibition. Thereby the establishment of the bio-suspensions viscosity seems impossible while basing on the conventional dependencies, such as employing Manley and Manson equation in this paper. These equations take into account neither the contact time of the phases and resulting in the imbibing effect of vegetal particles, nor the nonNewtonian behaviour of the dilute suspensions.

Due to the aforementioned complex sewage composition, the rheological behaviour of the liquid phase itself, which forms sewage, becomes a separate issue for consideration. The articles [14,15] highlighted the complexity of the rheological properties of the suspensions consisting of the non-Newtonian liquid. It is recommended to conduct the quantitative assessment of the imbibition effect of vegetal particles, which would further enable to determine the impact of the imbibing effect on the bio-suspension viscosity.

\section{References}

1. N. Eshtiaghi, F. Markis, S.D. Yap, J.C. Baudez P. Slatter, Water Res. 47, 5493-5510 (2013)

2. X-h. Wu, F. Wang, D-X. Sun, W-H. Yang, Exp. Therm. Fluid Sci. 35, 612-617 (2011)

3. N. Ratkovicha, W. Hornc, F.P. Helmusc, S. Rosenbergerc, W. Naessensd, I. Nopensd, T.R. Bentzen, Water Res. 47, 463-482 (2013)

4. I. Seyssiecq, J.H. Ferrasse, N. Roche, Biochem. Eng. J. 16, 41-56 (2003)

5. J.C. Baudez, J. Environ. Manage. 78, 232-239 (2006)

6. J.C. Baudez, F. Markis, N. Eshiaghi, P. Slatter, Water Res. 45, 5675-5680 (2011)

7. N. Eshtiaghi, S.D. Yap, F. Markis, J.C. Baudez P. Slatter, Waster Res. 46, 3014-3022 (2012)

8. M. Mori, I. Seyssiecq, N. Roche, Process Biochem. 41, 1656-1662 (2006)

9. V. Lotito, A.M., Lotito, J. Environ. Manage. 137, 189-196 (2014)

10. T. Li, Y. Wang, Y. Dong, J. Evnviron. Sci. 24, 1917-1922 (2012)

11. X. Cao, Z. Jiang, W. Cui, Y. Wang, P. Yang, Procedia Environ. Sci. 31, 113-121 (2016)

12. B.J. Konijn, O.B.J. Sanderink, N.P. Kruyt, Powder Technol. 266, 61-69 (2014)

13. M. Dziubiński, J. Prywer, Mechanika płynów dwufazowych (WNT, Warszawa, 2009)

14. J. Hapanowicz, Inż. Ap. Chem. 55, 136-138 (2016)

15. A. Szydłowska, J. Hapanowicz, Inż. Ap. Chem. 56, 26-28 (2017) 